\title{
Enhanced Bioavailability by Transdermal Administration of Pranoprofen Gels Containing Octanoic Acid to Rats
}

\author{
Jun-Shik Choi ${ }^{1}$ and Sang-Chul Shin ${ }^{2 *}$ \\ ${ }^{1}$ College of Pharmacy, Chosun University, Gwangju 501-759, Korea \\ ${ }^{2}$ College of Pharmacy, Chonnam National University, Gwangju 500-757, Korea
}

(Received July 4, 2008; Revised August 30, 2008; Accepted September 1, 2008)

\begin{abstract}
The pharmacokinetic parameters and bioavailability of pranoprofen from the gel were measured to determine the enhancing effect of octanoic acid on the transdermal absorption of pranoprofen in rats. $8 \mathrm{mg} / \mathrm{kg}$ of pranoprofen was administered from gel with octanoic acid (the enhancer group) or that without octanoic acid (the control group) via the transdermal route, and the results were compared with those obtained from the intravenously $(0.5 \mathrm{mg} / \mathrm{kg}$, IV group) or orally administered group (4 mg/kg, oral group). The AUC of the control, the enhancer, the IV, and the oral groups were $20.2 \pm 5.1,50.7 \pm 12.7,19.9 \pm 2.5$, and $70.5 \pm 17.6 \mathrm{ug} / \mathrm{ml} \cdot \mathrm{h}$ respectively. The average $C_{\max }$ of the control and the enhancer group were $0.93 \pm 0.23$ and $2.82 \pm 0.71 \mathrm{ug} / \mathrm{ml}$, respectively, and the mean $T_{\max }$ of the control and the enhancer group was $7.00 \mathrm{~h}$. The relative bioavailability of the transdermally administered pranoprofen gel containing octanoic acid was approximately 2.50 times higher than the control group, showing a relatively constant, sustained blood concentration with minimal fluctuation. This suggests that it might be feasible to develop a pranoprofen gel preparation containing an enhancer for the transdermal administration, which is more convenient dosage form than the oral dosage forms.
\end{abstract}

Keywords: Bioavailability, Pharmacokinetics, Bioadhesive, Pranoprofen, Enhancer, Transdermal administration.

\section{INTRODUCTION}

Pranoprofen, 2-(5H-[1] benzopyrano- [2, 3-b]-pyridin-7yl) propionic acid, has been widely used to treat diseases such as rheumatoid arthritis owing to its analgesic and anti-inflammatory properties (Fuccela et al., 1973; Luders et al., 1977). It was reported that pranoprofen is strongly bound to plasma protein (Kato et al., 1976) and shows rapid absorption and a urinary recovery of over $90 \%$ after the oral administration of a marketed conventional tablet to humans (Yoshio et al., 1990).

Since the NSAIDs are administered for a long term, it is important to avoid the first-pass effects and the gastrointestinal disturbances which might occur when orally administered. Therefore, it is desirable to administer the drugs via topical, pulmonary, and intramuscular routes in order to reduce the number of adverse reactions. Of the many drug delivery systems, there are many reports on transdermal NSAIDs delivery strategies (Huang et al.,

\footnotetext{
${ }^{*}$ Corresponding author

Tel: +82-62-530-2924, Fax: +82-62-530-2949

E-mail: shinsc@chonnam.ac.kr
}

1995; Yokomozo and Sagitani, 1996) because of its many advantages, which include bypassing the hepatic first pass effect, and the excellent accessibility, as well as the avoidance of gastrointestinal disturbances that might occur when administered orally. There is an increasing interest in the transdermal administration as a route for systemic drug delivery using bioadhesive preparations. However, the major limitation in transdermal delivery is the low permeation through the skin, resulting in a low absolute bioavailability. The use of penetration enhancers is a logical approach to increase drug permeation across the stratum corneum (Fang et al., 1998; Stott et al., 2001; Hadgraft et al., 1973; Monti et al., 2002; Vavrova et al., 2003).

In my previous paper (Shin and Cho, 2006), to improve the permeability of pranoprofen through the transdermal route, the pranoprofen gels containing octanoic acid showed the best enhancing effect. The aim of this study was to determine the feasibility of the transdermal delivery of pranoprofen gel containing octanoic acid by examining its in vivo absorption characteristics. 


\section{MATERIALS AND METHODS}

\begin{abstract}
Materials
The pranoprofen was obtained from the Kolong Pharm. Co. (Daejon, Korea). The Hydroxypropyl cellulose (HPMC $\mathrm{K} 100 \mathrm{M})$ was purchased from the Dow Chemical Co. (MI, USA) and poloxamer 407 was acquired from the BF Goodrich (USA). Methyl-4-aminobenzoate was purchased from the Aldrich Chemical Co. (WI, USA). The other chemicals of reagent grade were used without further purification.
\end{abstract}

\section{Preparation of pranoprofen gel containing an enhancer}

Two grams of HPMC were dissolved in hot water to make about $70 \mathrm{ml}$. Twenty grams of the poloxamer 407 were added to the HPMC solution with gentle stirring and the combined solution was left to stand overnight in a refrigerator to complete the polymer dissolution at approximately $5^{\circ} \mathrm{C}$ (Shin and Kim, 2000; Shin et al., 2000). Ten grams of octanoic acid and $160 \mathrm{mg}$ of pranoprofen were added to the above polymer solution with constant stirring. The preparation was then made to 100 $\mathrm{ml}$ with water. The pranoprofen solution for IV administration was prepared by dissolving $50 \mathrm{mg}$ of pranoprofen in $100 \mathrm{ml}$ of a $1 \%$ sodium bicarbonate solution.

\section{Animal experiments and drug administration}

Male Sprague-Dawley rats (270-300 g) were purchased from the Daehan Laboratory Animal Research Co. (Choongbuk, Korea), and were given free access to normal standard chow diet (Jail Chow, Korea) and tap water. The animals were housed, individually, in laminar flow cages maintained at $22 \pm 2^{\circ} \mathrm{C}, 50-60 \%$ relative humidity, under a $12 \mathrm{~h}$ light-dark cycle. The animals were kept in these facilities for at least one week prior to the experiment. This experiment was carried out in accordance with the "Guiding Principles in the Use of Animals in Toxicology" adopted by the Society of Toxicology (USA) in July 1989 and revised in March 1999. The animal care committee at Chosun University approved the present study. The Sprague-Dawley rats were fasted for at least $24 \mathrm{~h}$ prior to the experiments and were given water ad libitum. The rats were divided into four groups containing six rats each: the oral group (4 mg/kg of pranoprofen, oral), the enhancer group (8 $\mathrm{mg} / \mathrm{kg}$ of pranoprofen), the control group ( $8 \mathrm{mg} / \mathrm{kg}$ of pranoprofen) and the IV group ( $0.5 \mathrm{mg} / \mathrm{kg}$ of pranoprofen). Each rat was anaesthetized with ether, and the right femoral artery was cannulated with polyethylene tubing (PE-50, Intramedic,
Clay Adams, NJ, USA) for blood sampling.

For the transdermal administration, a pranoprofen gel (8 $\mathrm{mg} / \mathrm{kg}$ of pranoprofen) was applied to the abdominal skin where the hair had been shaved. In the oral group, pranoprofen $(4 \mathrm{mg} / \mathrm{kg})$ was suspended in $1.5 \mathrm{ml}$ of distilled water and administered orally to the rats. A pranoprofen injectable solution $(0.5 \mathrm{mg} / \mathrm{kg})$ was prepared by adding pranoprofen to saline containing $1 \%(\mathrm{w} / \mathrm{v})$ of sodium bicarbonate and injected through the femoral vein for $3 \mathrm{~min}$. After administering the dose, $0.5 \mathrm{ml}$ of blood specimens were taken at specific times from the cannula inserted into the femoral artery in heparinized glass tubes.

For the oral group, blood $(0.5 \mathrm{ml})$ was withdrawn from the femoral artery $0.25,0.5,1,2,4,5,6,9,12$, and $24 \mathrm{~h}$ after oral administration, and $0.017,0.1,0.25,0.5,1,2,4$, 8,12 , and $24 \mathrm{~h}$ after administering intravenously. For the transdermal gel groups, blood was withdrawn at $0.5,1,2$, $4,5,6,7,8,10,12$, and $24 \mathrm{~h}$ after transdermal administration.

After taking the blood specimens, heparinized physiological saline $(70 \mathrm{IU} / \mathrm{ml})$ was inserted into the set to prevent blood coagulation. The homeostasis of the rats was maintained by injecting the same volume of physiological saline after blood sampling. The blood samples were centrifuged at $5000 \mathrm{rpm}$ for $5 \mathrm{~min}$ to obtain the plasma samples $(0.2 \mathrm{ml})$. The plasma samples were stored at $-40^{\circ} \mathrm{C}$ until analyzed by HPLC.

\section{Determination of pranoprofen in rat plasma by HPLC}

The plasma concentrations of pranoprofen were determined by the HPLC assay method (Sagara et al., 1996; Nomura et al., 1993). Briefly, a $0.2 \mathrm{ml}$ aliquot of plasma was pipetted into a $15 \mathrm{ml}$ centrifuge tube, along with $50 \mathrm{ul}$ of an internal standard ( $5 \mathrm{ug} / \mathrm{ml}$ of methyl-4-benzoate), $0.2 \mathrm{ml}$ of citric acid and $1 \mathrm{ml}$ of toluene. It was then mixed vigorously for 2 min using a vortex and left to stand for 10 $\mathrm{min}$. After centrifugation for $10 \mathrm{~min}$ at $3000 \mathrm{rpm}, 0.8 \mathrm{ml}$ of the upper layer were transferred to a clean test tube and evaporated under $\mathrm{N}_{2}$ gas at $30^{\circ} \mathrm{C}$. The residue was dissolved in $0.6 \mathrm{ml}$ of the mobile phase by vortex mixing and centrifuged for $10 \mathrm{~min}$ at $13000 \mathrm{rpm}$. $20 \mathrm{ul}$ of this solution was then injected into the HPLC. The column used was a Symmetry $\mathrm{C}_{18}$ column $(4.6 \times 150 \mathrm{~mm}, 5 \mathrm{um}$, Waters Co., USA) maintained at ambient conditions. The mobile phase was a mixture of methyl alcohol: $0.01 \mathrm{M}$ acetic acid (55: $45 \mathrm{v} / \mathrm{v}, \mathrm{pH} 3.0$ ) and the flow rate was $1.0 \mathrm{ml} / \mathrm{min}$. The fluorescence detector wavelength was set at $298 \mathrm{~nm}$ for excitation and $360 \mathrm{~nm}$ for emission. The retention time of pranoprofen and the internal standard from the plasma 
chromatogram were $9.0 \mathrm{~min}$ and $3.0 \mathrm{~min}$, respectively (Fig. 1).

\section{Pharmacokinetics analysis}

The pharmacokinetic parameters in terms of the one compartment open model were calculated by nonlinear least square regression using the MULTI program (Yamaoka, 1981). The parameter value was obtained by fitting to the simplex method when the AIC (Akaike's information criterion) value was the lowest. The area under the plasma concentration-time curves (AUC) was calculated using the trapezoidal rule.

The maximum plasma concentration $\left(\mathrm{C}_{\max }\right)$ and the time to reach the maximum plasma concentration $\left(T_{\max }\right)$ were determined from the experimental dada. The elimination rate constant $\left(\mathrm{K}_{\mathrm{el}}\right)$ was calculated by regression analysis from the slope of the line, and the half-life $\left(\mathrm{t}_{/ 2}\right)$ of pranoprofen was obtained by $0.693 / \mathrm{K}_{\mathrm{el}}$. The absolute bioavailability of pranoprofen after the transdermal (TD) administration (8 $\mathrm{mg} / \mathrm{kg}$ ) compared with the IV administration $(0.5 \mathrm{mg} / \mathrm{kg})$ was calculated as follows:

$$
\text { Absolute bioavailability (A.B. \%) }=\frac{\mathrm{AUC}_{\mathrm{TD}}}{\mathrm{AUC}_{\mathrm{IV}}} \times \frac{\mathrm{IV}_{\text {dose }}}{\mathrm{TD}_{\text {Dose }}} \times 100
$$

The relative bioavailability of pranoprofen after the transdermal administration (TD) was calculated as following:

$$
\text { Relative bioavailability (R.B \%) }=\frac{A \cup C_{T D}}{A_{\text {oral }}} \times 100
$$

\section{Statistical analysis}

All the means are presented with their standard deviation (Mean \pm S.D.). An unpaired student's t-test was used to compare the enhancer group with the control group. The differences were considered significant at $p<0.01$.

\section{RESULTS AND DISCUSSION}

\section{Pharmacokinetics}

\section{Area under the concentration-time curve}

One of the prerequisites for examining the biopharmaceutical aspects of the transdermal absorption of pranoprofen is that there should be a correlation between the pharmacokinetic parameter for IV and the transdermal administration of pranoprofen.

Fig. 2 shows the plasma-time concentration curve for pranoprofen after the transdermal administration of the pranoprofen gel ( $8 \mathrm{mg} / \mathrm{kg}$ of pranoprofen) compared with the IV administration to rats of a single $0.5 \mathrm{mg} / \mathrm{kg}$ dose of pranoprofen. Table I shows the pharmacokinetic parameters of pranoprofen via transdermal administration of pranoprofen gels containing octanoic acid comparing with the oral and the IV administration. The average area under the serum concentration-time of the intravenous administration was approximately $9.89 \pm 2.47 \mathrm{ug} / \mathrm{ml} \cdot \mathrm{h}$. Following the transdermal administration of a single $8 \mathrm{mg} / \mathrm{kg}$ dose of pranoprofen, the $\mathrm{AUC}_{024 \mathrm{~h}}$ of the pranoprofen gel with the enhancer was $50.71 \pm 12.68 \mathrm{ug} / \mathrm{ml} \cdot \mathrm{h}$ and that without the enhancer was $20.22 \pm 5.08 \mathrm{ug} / \mathrm{ml} \cdot \mathrm{h}$ (Table I). There were significant differences between the formulations $(p<0.01)$. The absolute bioavailability of the $\mathrm{AUC}_{024 \mathrm{~h}}$ value of the transdermal administration of the gel without an enhancer was $13 \%$ compared with that of the intravenous administration. However, the absolute bioavailability of the $\mathrm{AUC}_{0 \rightarrow 24 \mathrm{~h}}$ value of transdermal administration of pranoprofen gel containing octanoic acid was approxi-
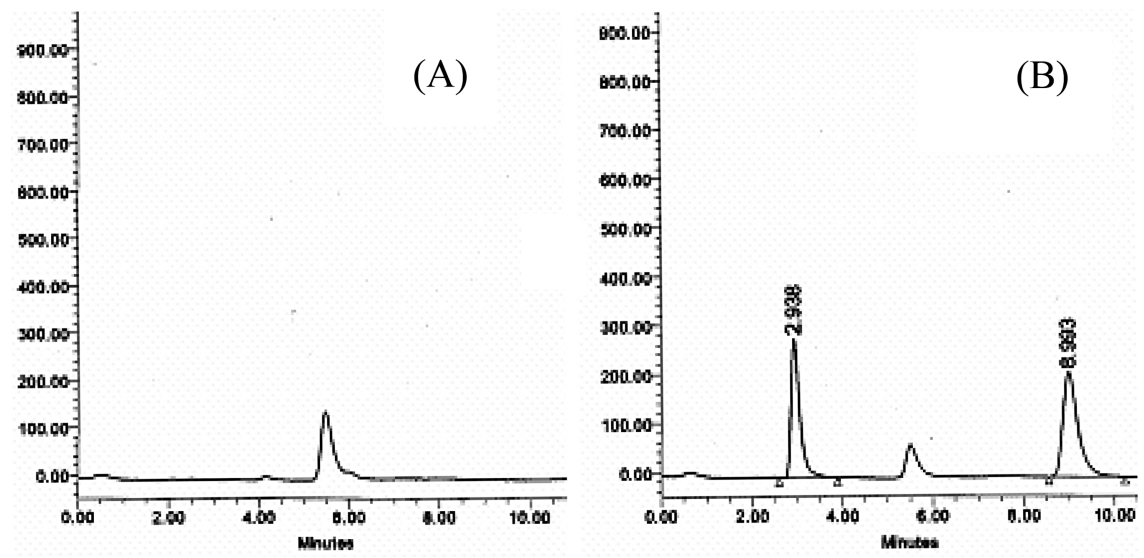

Fig. 1. Chromatograms of the blank plasma $(A)$ and the plasma spiked $(B)$ with the internal standard (2.94 min) and pranoprofen (8.99 min). 


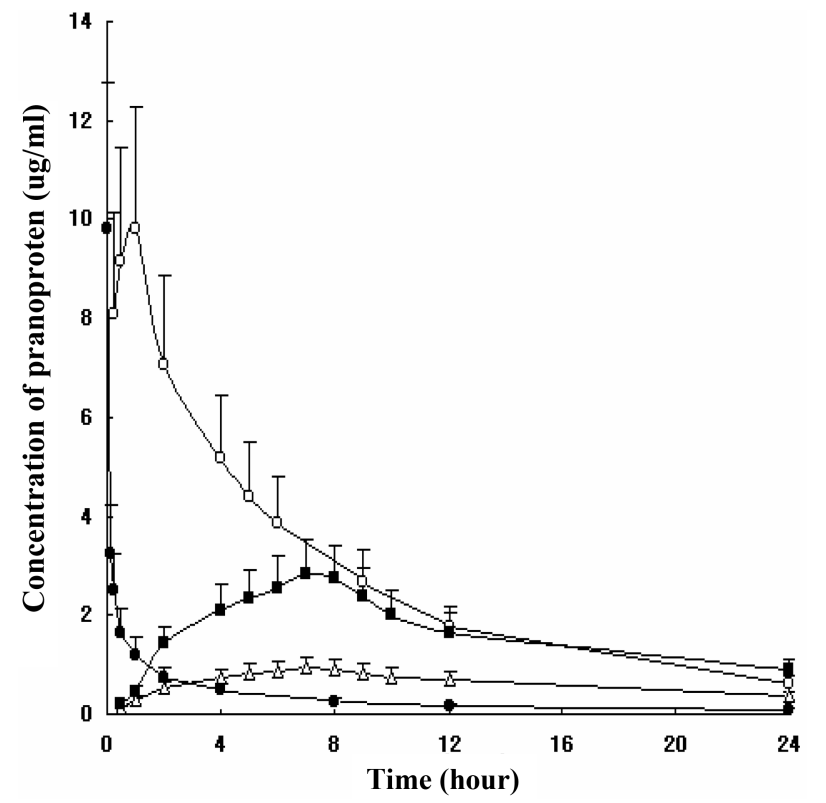

Fig. 2. Mean plasma concentration-time profile of pranoprofen following the transdermal administration of the gel $(8 \mathrm{mg} / \mathrm{kg})$ containing an enhancer to the rats. The error bar represents the standard deviation of the mean $(n=6)$.

$\triangle$ : transdermal administration of gel without octanoic acid (control group, $8 \mathrm{mg} / \mathrm{kg}$ );

: transdermal administration of gel with octanoic acid (enhancer group, $8 \mathrm{mg} / \mathrm{kg}$ );

$\bigcirc$ : oral administration (oral group, $4 \mathrm{mg} / \mathrm{kg}$ );

: intravenous administration (IV group, $0.5 \mathrm{mg} / \mathrm{kg}$ ).

mately $32 \%$ compared with the intravenous administration. When the pranoprofen gel containing octanoic acid was administered to the rats via the transdermal route, the relative bioavailability was approximately two and half times higher than that of the gel without enhancer (control group), which means the enhanced absorption.

The transdermal administration of pranoprofen gel containing octanoic acid to rats showed a relatively sustained, enhanced blood concentration profile with minimal fluctuations.

\section{Peak concentration $\left(C_{\max }\right)$ and peak time $\left(T_{\max }\right)$}

The $C_{\max }$ value of the transdermal pranoprofen gels shows that the enhancer group had higher value of 2.82 $u g / m l$ than that of the control group, $0.93 \mathrm{ug} / \mathrm{ml}(p<0.01)$. The $T_{\max }$ of the pranoprofen gel in the enhancer and control group were both $7.0 \mathrm{~h}$, and the terminal half lives $\left(\mathrm{t}_{1 / 2}\right)$ of pranoprofen in the control and enhancer groups varied between 11-12 $\mathrm{h}$ (Table I).

The relative bioavailability of the enhancer group was approximately two and half times higher than that of the control group. In previous papers (Shin et al., 2000; Shin et al., 2001) showed that the changes in the thermal profile seen with fatty acid-treated skin suggested that its incorporation had different fluidizing effects on lipids of the stratum corneum and resulted decreased lipid order.

The transdermal administration of the gel containing an octanoic acid showed slightly sustained and enhanced absorption profile. In addition, the $t_{1 / 2}$ of the pranoprofen gel containing octanoic acid was prolonged significantly $(\mathrm{p}<0.01)$.

\section{CONCLUSIONS}

The transdermal administration of a pranoprofen gel

Table I. Pharmacokinetic parameters of pranoprofen via transdermal administration of pranoprofen gel $(8 \mathrm{mg} / \mathrm{kg}$ of pranoprofen) containing octanoic acid (enhancer) compared with the oral and the IV administration

\begin{tabular}{|c|c|c|c|c|}
\hline \multirow{2}{*}{ Parameters } & \multirow{2}{*}{$\begin{array}{c}\text { IV } \\
(0.5 \mathrm{mg} / \mathrm{kg})\end{array}$} & \multicolumn{2}{|c|}{ Transdermal Gel (8 mg/kg) } & \multirow{2}{*}{$\begin{array}{c}\text { Oral } \\
(4 \text { mg/kg) }\end{array}$} \\
\hline & & No enhancer & Enhancer & \\
\hline $\mathrm{AUC}_{0 \rightarrow 24 \mathrm{~h}}(\mu \mathrm{g} / \mathrm{ml} \cdot \mathrm{h})$ & $9.89 \pm 2.47$ & $20.22 \pm 5.05$ & $50.71 \pm 12.68^{* *}$ & $70.45 \pm 17.61$ \\
\hline $\mathrm{C}_{\max }(\mu \mathrm{g} / \mathrm{ml})$ & & $0.93 \pm 0.23$ & $2.82 \pm 0.71^{*}$ & $9.81 \pm 2.45$ \\
\hline $\mathrm{T}_{\max }(\mathrm{h})$ & & 7.0 & 7.0 & 1.0 \\
\hline $\mathrm{t}_{1 / 2}(\mathrm{~h})$ & $8.0 \pm 2.0$ & $11.9 \pm 2.9$ & $11.3 \pm 2.8$ & $7.0 \pm 1.8$ \\
\hline A.B. (\%) & & 12.8 & 32 & 89 \\
\hline R.B. (\%) & & 14.4 & 36 & 100 \\
\hline
\end{tabular}

Each value represents the mean \pm S.D $(n=6),{ }^{*} p<0.05,{ }^{* *} p<0.01$ compared to control

$\mathrm{AUC}_{0 \rightarrow 24 \mathrm{~h}}$ : area under the plasma concentration-time curve from $0 \mathrm{~h}$ to $24 \mathrm{~h}$.

$\mathrm{C}_{\max }$ : peak concentration

$\mathrm{T}_{\max }$ : time to reach peak concentration

$t_{1 / 2}:$ terminal half-life

A.B. (\%): absolute bioavailability

R.B (\%): relative bioavailability, $A \cup C$ rate compared to $A \cup C_{\text {oral }}$ 
containing octanoic acid to rats showed a relatively sustained and enhanced blood concentration profile with minimal fluctuations. Based on these results, it might be feasible to develop a pranoprofen gel preparation containing an enhancer for the transdermal administration, which is more convenient dosage form than the oral dosage forms.

\section{REFERENCES}

Fang, J.Y., Lin, H.H., Chen, H.I. and Tsai, Y.H. (1998). Development and evaluation on transdermal delivery of enoxacin via chemical enhancers and physical iontophoresis. J. Cont. Rel. 54, 293-304.

Fuccela, L. M., Goldaniga, G. C., Moro, E., Tamassia, V. Tosolini, G. P. and Valzelli, G. (1973). Fate of analgesic and antiinflammatory drug K4277 after oral administration to man. Dur. J. Clin. Pharmacol. 6, 256-260.

Hadgraft, J., Hadgraft, J. W. and Sarkany, I. (197)3. The effects of thermodynamic activity on percutaneous absorption. $J$. Pharm. Pharmacol., 25, 122-123.

Huang, Y. B., Wu, P. C., Ko, H. M. and Tsai, Y. H. (1995). Cardamon oil as a skin permeation enhancer for indomethacin, piroxicam and diclofenac. Int. J. Pharm. 126, 111-117.

Kato, Y., Arima, N. and Nishimine, H. (1976). Studies on antiinflammatory agents. Absorption, excretion, distribution and metabolism of 2-(5h-[1] benzopyrano [2, 3-b] pyridin-7-yl) propionic acid (Y-8004) in rats and mice. Yakugaku Zasshi 96, 819-826.

Luders, R. C., Maggio-Cavaliere, M. B., Egger, H., Chemiken, H. T. L., Gum, D. B. and Resnick, O. (1977). Disposition of pranoprofen, a new anti-inflammatory drug. Clin. Pharmacol. Ther. 21, 721-730.

Mizobuchi, T., Oji, Y. and Rokusa, K. (1986). Sheet type buccal adhesive tapes for sustained drug delivery in oral cavity, Jpn. Kokai Tokko Koho, 87, 178513-178518.

Monti, D., Chetoni, P., Burgalassi, S., Najarro, M., Saettone, M.F. and Boldrini, E. (2002). Effect of different terpene-containing essential oils on permeation of estradiol through hairless mouse skin. Int. J. Pharm. 237, 209-214.

Nakayama, A., Oda, M., Miyazaki, S. and Takeda, M. (1994). Oral mucosal adhesive tablets of indomethacin using chitosan and sodium alginate, Yakuzaigaku 54, 185-189.

Nomura, T., Imai, T. and Otagiri, M. (1993). Stereoselective disposition of pranoprofen, a nonsteroidal anti-inflammatory drug in rabbits. Biol. Pharm. Bull. 6, 298-303.

Park, Y. H., Chung, B. H., Cha, B. J. Kwon, J.W. and Yang, J. I. (1990). Preparation and evaluation of sustained release oral adhesive type acyclovir tablets, Yakhak Hoeji 34, 155-160.

Sagara K, Yamada I, Matsuura Y, Kawata M. and Shibata M. (1996). Gastrointestinal physiology-regulated dogs for bioavailability evaluation of an oral controlled-release dosage form composed of pulsatile release granules. Biol. Pharm. Bull. 19, 1184-1188.

Saito, S., Sadamoto, K., Ishikawa, Y., Machida, Y. and Nagai, T. (1990). Preparation and evaluation of oral mucosal adhesive film, Yakuzaigaku 50, 347-352.

Shin, S. C., Cho, C. W. and Oh, I. J. (2000). Enhanced efficacy by percutaneous absorption of piroxicam from the poloxamer gel in rats. Int. J. Pharm. 193, 213-218.

Shin, S. C. and Kim, J, Y. (2000). Enhanced permeation of triamcinolone acetonide through the buccal mucosa. Eur. J. Pharm. Biopharm. 50, 217-220.

Shin S. C. Shin, E. Y. and Cho, C. W. (2000). Enhancing effects of fatty acids on piroxicam permeation through rat skins, Drug Dev. Ind. Pharm., 26, 563-566.

Shin, S. C. Cho, C. W. and Oh, I. J. (2001). Effects of non-ionic surfactants as permeation enhancers towards piroxicam from the poloxamer gel through rat skins. Int. J. Pharm. 222, 199203.

Shin, S. C. and Cho, C. W. (2006). Enhanced transdermal delivery of pranoprofen from the bioadhesive gels, Arch. Pharm. Res. 29, 928-933.

Stott, P.W., Williams, A.C. and Barry, B.W. (2001). Mechanistic study into the enhanced transdermal permeation of a model $\beta$-blocker, propranolol, by fatty acids: a melting point depression effect. Int. J. Pharm. 219, 161-176.

Vavrova, K., Hrabalek, A., Doleal, P., Holas, T. and Zbytovska, J, (2003). L-Serine and glycine based ceramide analogues as transdermal permeation enhancers: polar head size and hydrogen bonding. Bioorg. \& Medic. Chem. Letters. 13, 23512353.

Yamaoka, K., Tanigawara, Y., Nakagawa, and T., Uno, T. (1981). A pharmacokinetic analysis program (multi) for microcomputer. J. Pharmacobiodyn. 4, 879-885.

Yokomozo, Y., Sagitani, H. (1996). Effects of phospholipids on the percutaneous penetration of indomethacin through the dorsal skin of guinea pigs. J. Cont. Rel. 38, 267-274.

Yoshio, I., Iwata, A., Isobe, M., Takamatsu, R., Higashi, M. (1990). The pharmacokinetics of pranoprofen in humans. Yakugaku Zasshi 110, 509-515. 